\title{
WIRELESS INFORMATION AND ENERGY TRANSFER: TRADEOFF FOR FAIR RESOURCE ALLOCATION
}

\author{
Hristina Čingoska, Zoran Hadži-Velkov, Ivana Nikoloska \\ Faculty of Electrical Engineering and Information Technologies, \\ "Ss. Cyril and Methodius" University in Skopje, \\ Rugjer Bošković bb, P.O. box 574, 1001 Skopje, Republic of Macedonia \\ zoranhv@feit.ukim.edu.mk
}

\begin{abstract}
A b s t r a c t: In this paper, we study two schemes for the fair resource allocation in wireless powered communication networks (WPCNs): a non-orthogonal multiple access (NOMA) scheme, and a proportional fair (PF) scheduling scheme. The considered WPCN consists of a base station (BS) that broadcast radio frequency (RF) energy over the downlink, and $N$ energy harvesting users (EHUs). If NOMA is employed, all EHUs concurrently transmit information over the uplink with successive interference cancellation employed at the BS. If PF scheduling is employed, a single EHU is selected for uplink transmission in each frame. For both schemes, we arrive at optimal allocations for the BS transmit power and the time sharing between uplink and downlink transmissions that maximize the uplink sum-rate, while maintaining high level of system fairness. For the PF scheme, we also derive the optimal scheduling policy. Compared to the state-of-the art schemes based upon time division multiple access (TDMA), both schemes significantly improve the system fairness at the expense of minor (or nonexistent) rate degradation.
\end{abstract}

Key words: energy harvesting; wireless powered communication networks; non-orthogonal multiple access; successive interference cancelation; proportional fair scheduling

\section{БЕЗЖИЧЕН ПРЕНОС НА ИНФОРМАЦЈА И ЕНЕРГИЈА СО ПРАВИЧНА РАСПРЕДЕЛБА НА РЕСУСРСИ}

А п с т р а к т: Во овој труд се проучени две шеми за фер распределба на ресурсите во безжично напојувани телекомуникациски мрежи (WPCN): шема со не-ортогонален повеќекратен пристап (NOMA) и шема со пропорционално опслужување (PF). Во разгледуваната мрежа базната станица емитува радиофреквенциско зрачење кон повеќе крајни корисници, кои ја прифаќаат енергијата од тоа зрачење. Ако се примени шемата NOMA, сите крајни корисници истовремено праќаат информација кон базната станица, а таа врши последователно поништување на интерференцијата предизвикана од примените сигнали. Ако се примени шемата PF, само една избрана станица во еден момент праќа информација кон базната станица. За двете шеми е определена оптимална распределба на излезната моќност на базната станица и оптимална распределба помеѓу времињата за праќање информација и енергијата, со цел да се максимира вкупната податочна брзина кон базната станица, а истовремено да се зачува принципот за фер искористување на системските ресурси. Во случајот на шемата PF, исто така е определена полисата за оптимално опслужување. Во споредба со познатите шеми со временски ортогонален повеќекратен пристап (TDMA), двете предложени шеми значително ја подобруваат рамноправноста меѓу крајните корисници, на сметка на незначително намалување на вкупната податочна брзина кон базната станица.

Клучни зборови: прифаќање енергија; безжичо напојувани телекомуникациски мрежи (WPCN); неортогонален повеќекратен пристап; последователно поништување на интерференција; шема со пропорционално опслужување (PF)

\section{INTRODUCTION}

Recent advances in ultra-low power wireless communications and energy harvesting (EH) technologies have made self-sustainable devices fea- sible. Typically, the major concern for these devices is battery life and replacement. Applying energy harvesting techniques to these devices can significantly extend battery life and sometimes even entirely eliminate the need for a battery $[1,2]$. 
However, energy harvesting from the environment (such as, solar or wind) may not provide a stable and continuous power supply to the communication system. Instead, energy may be harvested from a radio frequency (RF) radiation from dedicated power sources. Therefore, the RF energy harvesting has emerged as a revolutionary technology for the energy-constrained wireless networks, such as the sensor and ad hoc networks [1-3].

Networks of nodes that utilize both information transmission and energy transmission are known as wireless-powered communication networks (WPCNs) [4-6]. The design optimization of WPCNs so far typically focuses on maximization of the sum-rate over the uplink, which is a spectrally efficient method, but yet biased and unfair in terms of resource sharing among the EHUs. In particular, due to the large-scale fading, the EHUs at closer distances to the BS can transmit at much higher rates compared to the more distant EHUs. Thus, conventional sum-rate maximization allows only EHUs close to the BS to achieve a much higher aggregate rate compared to the cell-edge EHUs.

In order to tackle this issue, this paper proposes two different schemes that facilitate fair resource allocation in the WPCNs: (a) non-orthogonal multiple access (NOMA), and (b) proportionally fair (PF) scheduling. When NOMA is employed, all network users simultaneously transmit their codewords towards a common receiver, which decodes them by successive interference cancellation (SIC) [7-9]. [10] solves an weighted sum-rate maximization problem in order to derive achievable rate regions and compares the performances between the approach with joint resource allocation and the one when only optimal time allocation is considered. On the other hand, PF scheduling is widely applied to today's conventional cellular systems [11]. In the context of EH communications, [12] determines the optimum offline resource allocation on an EH downlink [13] studies uplink sum-rate maximization with short-term energy harvesting and the applicability of a proposed suboptimal online algorithm, while [14] studies uplink sum-rate maximization with long-term energy harvesting with a complex battery model and processing cost.

In this paper, we study WPCN that employs short-term energy harvesting with a simple battery model. For both of these schemes, by solving a sum-rate maximization problem we derive the expressions for optimal allocations for the BS transmit power and the time sharing between the uplink and downlink transmissions. For the PF scheme, we also derive the optimal online scheduling policy.

\section{SYSTEM AND CHANNEL MODEL}

The WPCN is assumed to operate in a random fading environment, consisting of a base station (BS) and $N$ EHUs, all equipped with a single antenna. The EHUs are equipped with rechargeable EH batteries that store the harvested energy. Let the time be divided into epochs of equal duration $T$. Each epoch is subdivided into two consecutive phases: an EH phase, during which the BS broadcasts RF energy to the EHUs, and an IT phase (Figure 1). In the case of the NOMA scheme, the IT phase consists of multiple concurrent transmissions from all the EHUs (Figure 2), whereas, in the case of the PF scheduling, the IT phase consists of a single transmission of the scheduled EHU (Figure 3). In epoch $i$, the duration of the EH phase is $\tau_{i} T$, whereas the duration of the IT phase is $(1-$ $\left.\tau_{\mathrm{i}}\right) T$. During the IT phase, the EHUs consume the total amount of energy harvested during the preceding EH phase.

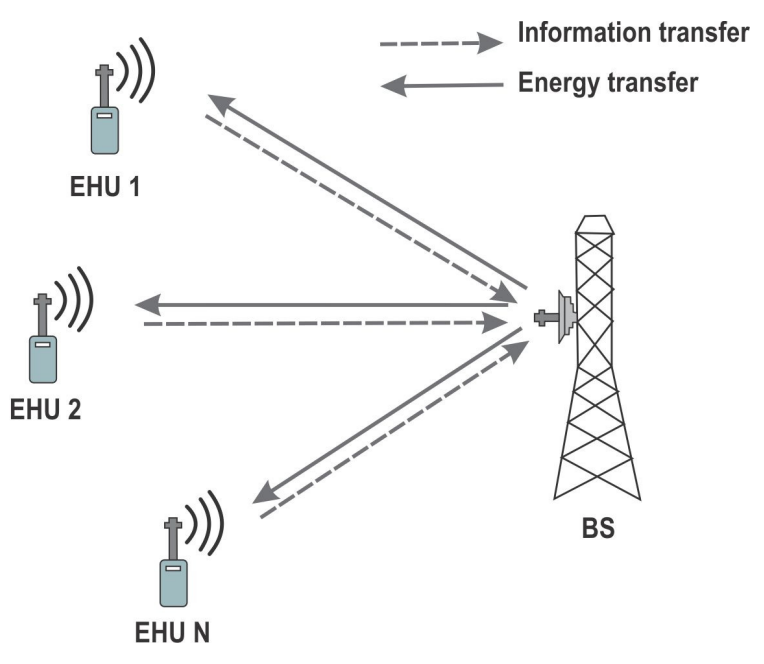

Fig. 1. System model

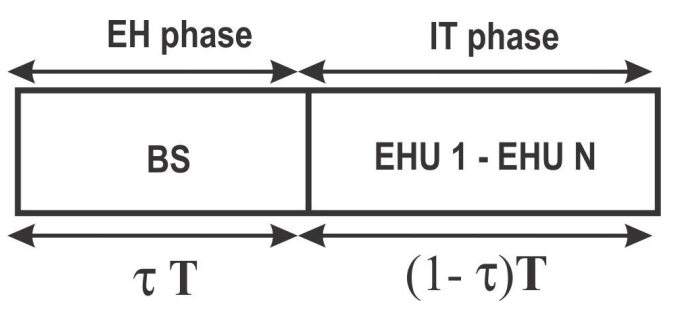

Fig. 2. NOMA epoch 


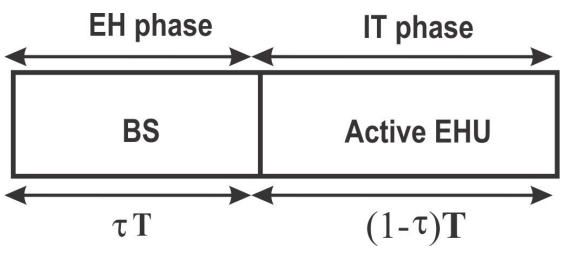

Fig. 3. Epoch with PF scheduling

The fading between the BS and EHU $n$ $(1 \leq n \leq N)$ is assumed to be stationary and ergodic random process, which follows the block fading model (i.e. the channel is constant during a single block but changes independently from one block to the next). We assume that the duration of each fading block is equal to $T$, and coincides with a single epoch. In epoch $i$, let the fading power gain of the BSBS-EHU ${ }_{n}$ channel be denoted by $x_{n^{\prime}}(i)$. For convenience, the corresponding downlink (BS-EHU ${ }_{n}$ ) and uplink (EHU $\left.\mathrm{B}_{\mathrm{n}} \mathrm{BS}\right)$ channels are assumed to be reciprocal, although the generality of our results is unaffected by this assumption. These gains are normalized by the additive white gaussian noise (AWGN) at the receiver $N_{0}$, yielding $x_{n}(i)=x_{n^{\prime}}(i) / N_{0}$. The average value of $x_{n}(i)$ is denoted by $\Omega_{n}=E\left[x_{n^{\prime}}(i)\right] / N_{0}$, where $E[\cdot]$ denotes expectation. The BS is assumed to control and coordinate the uplink and downlink transmissions, and therefore is assumed to to have perfect channel state information (CSI) of all $N$ fading links, $\left\{x_{n}(i)\right\}_{n=1}^{N}$, in each epoch. The transmit power of the BS in epoch $i$ is denoted by $p_{i}$. We assume that the power of the BS has to satisfy an average power constraint, $P_{a v g}$ (i.e. $E\left[p_{i}\right] \leq P_{\text {avg }}$ ), and a maximum power constraint, $P_{\max }$ (i.e. $0 \leq p_{i} \leq P_{\max }$ ).

\section{FAIR RESOURCE ALLOCATION}

In the following subsections we derive expressions for the optimal BS transmit power and the duration of the EH and IT phase for two scenarios: (a) when NOMA is employed in the WPCN, and all of the EHUs transmit simultaneously over the uplink; (b) when PF scheduler selects a single EHU for uplink transmission.

\section{Non-orthogonal multiple access}

In case of NOMA, the harvested energy by $n$th EHU is $E_{n}(i)=\eta_{n} x_{n}(i) N_{0} p_{i} \tau_{i} T$, where $\eta_{n}$ is the energy harvesting efficiency of $n$-th EHU. Using the notations, we can obtain the transmit power of $n$-th EHU during the successive IT phase in epoch $i$ as

$$
P_{n}(i)=\frac{E_{n}(i)}{\left(1-\tau_{i}\right) T}=\frac{\eta_{n} x_{n}(i) N_{0} p_{i} \tau_{i}}{1-\tau_{i}} .
$$

On the other hand, the rate of $n$-th EHU, denoted by $R_{n}(i)$, depends on the decoding order at the BS. Without loss of generality, we enumerate the EHUs according to the order od increasing average fading gains (i.e. $\Omega_{1} \leq \Omega_{2} \leq \ldots \leq \Omega_{N}$ ).

Given $\tau_{i}, P_{n}(i), \forall n$, the $n$-th EHU in epoch $i$ transmits a Gaussian distributed codeword (comprised of infinitely many symbols during the time $\left(1-\tau_{i}\right) T$. The actual achievable rate of $n$-th EHU, $\forall n$, in epoch $i$ is given by

$$
R_{n}(i)=\left(1-\tau_{i}\right) \log \left(1+\frac{P_{n}(i) x_{n}(i)}{1+\sum_{k=1}^{n-1} P_{k}(i) x_{k}(i)}\right) \text {. }
$$

The decoding order of the proposed NOMA scheme is based upon the long-term channel statistics, with fixed decoding order at the BS that is inverse to the distances of the EHUs from the BS. Please note that, compared to the duration of a single epoch, the time to decode information of all EHUs at the BS (employing SIC) is negligible, which is a reasonable assumption. The BS decodes the EHUs' codewords in the order $N, N-1, \ldots, 2,1$ and uses SIC: The EHU $N$ is decoded first while experiencing interference from the remaining $N-1$ EHUs. The EHU $N-1$ is decoded second while experiencing interference from EHUs $N-2, \quad N-3, \ldots, 2,1$. Finally, the EHU with smallest average fading power, the EHU 1 is decoded last in the absence of interference. It is worth mentioning that the decoding order does not affect the sum-rate of the EHUs. It only affects the value of the individual rates of the EHUs, and consequently the system fairness.

Using (2) the average achievable rate of EHU $n, \forall n$, over M epochs is given by

$$
\bar{R}_{n}=\lim _{M \rightarrow \infty} \frac{1}{M} \sum_{i=1}^{M}\left(1-\tau_{i}\right) \log \left(1+\frac{P_{n}(i) x_{n}(i)}{1+\sum_{k=1}^{n-1} P_{k}(i) x_{k}(i)}\right) \text {, }
$$


Assuming $M \rightarrow \infty$ epochs we can formulate the following sum-rate maximization problem:

$$
\underset{p_{i}, \tau_{i}, \forall i}{\operatorname{Maximize}} \sum_{n=1}^{N} \bar{R}_{n}
$$

s.t.

$$
\begin{aligned}
& C 1: \frac{1}{M} \sum_{i=1}^{M} p_{i} \tau_{i} \leq P_{a v g} \\
& C 2: 0 \leq p_{i} \leq P_{\max }, \\
& C 3: 0<\tau_{i}<1,
\end{aligned}
$$

where $\bar{R}_{n}$ is given by (3).

The solution of (4) is given by the following theorem.

Theorem 1. The optimal BS transmit power, $p_{i}^{*}$, is given by

$$
p_{i}^{*}=\left\{\begin{array}{cc}
P_{\max }, & \lambda<b(i) \\
0, & \text { otherwise }
\end{array}\right.
$$

The optimal duration of the EH phase $\tau_{i}^{*} T$, is found as the root of the following transcendental equation,

$$
\begin{gathered}
\log \left(1+\frac{b(i) P_{\max } \tau_{i}^{*}}{1-\tau_{i}^{*}}\right)+\lambda P_{\max }= \\
=\frac{b(i) P_{\max }}{1-\tau_{i}^{*}+b(i) P_{\max } \tau_{i}^{*}}
\end{gathered}
$$

where

$$
b(i)=N_{0} \sum_{n=1}^{N} \eta_{n} x_{n}^{2}(i) .
$$

The constant $\lambda$ is found from

$$
(1 / M) \sum_{i=1}^{M} p_{i}^{*} \tau_{i}^{*}=P_{a v g} .
$$

Proof: Please refer to Appendix A.

\section{Proportional fair scheduling}

We aim at determining an opportunistic scheduling policy that achieve proportional fairness in the considered WPCN. Let the EHU $s_{i}$ be the scheduled user in epoch $i$, which is selected opportunistically from among the EHUs. The remaining $N-1$ EHUs are silent (i.e. they neither harvest energy nor transmit information). The amount of harvested energy by EHU $s_{i}$ during the EH period is given by

$$
E_{s_{i}}(i)=\eta_{s_{i}} x_{s_{i}}(i) N_{0} p_{i} \tau_{i} T
$$

where $\eta_{s_{i}}$ is the energy harvesting efficiency of the scheduled EHU, and $x_{s_{i}}(i)$ is the normalized fading power gain of the channel between the scheduled EHU and the BS. During the IT phase, EHU $s_{i}$ spends all of its harvested energy, $E_{s_{i}}$, for transmitting information to the BS. In particular, the EHU $s_{i}$ in epoch $i$ can transmit a codeword of duration $\left(1-\tau_{i}\right) T$ with an output power,

$$
P_{s_{i}}(i)=\frac{E_{s_{i}}(i)}{\left(1-\tau_{i}\right) T}=\frac{\eta_{s_{i}} x_{s_{i}}(i) N_{0} p_{i} \tau_{i}}{\left(1-\tau_{i}\right)}
$$

and an information rate $\log \left(1+P_{s_{i}}(i) x_{s_{i}}(i)\right)$. The actual achievable rate of the scheduled EHU $s_{i}$ in that epoch is given by:

$$
r_{s_{i}}(i)=\left(1-\tau_{i}\right) \log \left(1+P_{s_{i}}(i) x_{s_{i}}(i)\right) .
$$

Let us now define the indicator variable

$$
I_{n}(i)= \begin{cases}1, & \text { if } n=s_{i} \\ 0, & \text { if } n \neq s_{i}\end{cases}
$$

denoting whether EHU $n$ is activated or not. Using (10) and (11) the average achievable rate of $E H U_{n}$ over M epochs is given by

$$
\bar{R}_{n}=\lim _{M \rightarrow \infty} \frac{1}{M} \sum_{i=1}^{M} I_{n}(i) r_{n}(i)
$$

By definition, PF scheduling is aimed at maximizing the product of the achievable rates of all users, or, equivalently the sum of the logarithms of the individual rates [12, 15]. Following this approach, we aim at maximizing the objective function $\sum_{n=1}^{N} \log \bar{R}_{n}$ and the PF optimization problem is defined as follows:

$$
\underset{p_{i}, \tau_{i}, I_{n}(i)}{\operatorname{Maximize}} \sum_{n=1}^{N} \log \bar{R}_{n}
$$

s.t.

$$
\begin{aligned}
& C 1^{\prime}: \quad \frac{1}{M} \sum_{i=1}^{M} p_{i} \tau_{i} \leq P_{a v g} \\
& C 2^{\prime}: \quad 0 \leq p_{i} \leq P_{\max }, \forall i
\end{aligned}
$$




$$
\begin{aligned}
C 3^{\prime}: & 0<\tau_{i}<1, \forall i \\
C 4^{\prime}: & I_{n}(i) \in\{0,1\}, \forall i, n, \\
C 5^{\prime}: & \sum_{n=1}^{N} I_{n}(i) \leq 1, \forall i .
\end{aligned}
$$

Theorem 2. The solution of (13) is given by

$$
s_{i}=\arg \max _{n} \frac{r_{n}(i)}{\bar{R}_{n}} .
$$

Moreover, the optimal allocations of the BS transmit power and the duration of the $\mathrm{EH}$ phase are respectively given by

$$
\begin{gathered}
p_{i}^{*}=\left\{\begin{array}{cc}
P_{\max }, & a_{s_{i}}(i)>\lambda \bar{R}_{s_{i}} \\
0, & \text { otherwise, }
\end{array}\right. \\
\tau_{i}^{*}=1-\frac{a_{s_{i}}(i) P_{\max }}{a_{s_{i}}(i) P_{\max }-1}\left(1+\frac{1}{W\left(\frac{a_{s_{i}}(i) P_{\max }-1}{e^{1-\bar{R}_{s_{i}} \lambda P_{\max }}}\right)}\right)^{-1},
\end{gathered}
$$

where $a_{s_{i}}(i)=N_{0} \eta_{s_{i}} x_{s_{i}}^{2}(i)$. Note that $W(\cdot)$ denotes the Lambert $W$ function. The constant $\lambda$ is found from $(1 / M) \sum_{i=1}^{M} p_{i}^{*} \tau_{i}^{*}=P_{\text {avg }}$.

Proof: Please refer to Appendix B.

\section{NUMERICAL RESULTS}

In this section, we provide simulation results to complement the analysis above. Since Rayleigh fading is considered, $x_{n}^{\prime}(i)$ follow an exponential distribution. The deterministic path loss is calculated as $E\left[x_{n}^{\prime}(i)\right]=10^{-3} D_{n}^{-\alpha}$, where $D_{n}$ is the distance of the $n$-th EHU to the BS. The pathloss at a reference distance of $1 \mathrm{~m}$ is set to $30 \mathrm{~dB}$, and the pathloss exponent is set to $\alpha=3$. We assume an AWGN power equal to $N_{0}=2 \cdot 10^{-12} \mathrm{~W}$. Thus, $\Omega_{n}=10^{-3} D_{n}^{-3} / N_{0}$. We consider that one half (i.e. $\mathrm{N} / 2$ ) of the EHUs are placed at a distance of $D_{1}=10 \mathrm{~m}$, yielding to $\Omega_{n}=10^{6}$ and the other half (i.e. N/2) of the EHUs at a distance of $D_{2}=12.5 \mathrm{~m}$ from the BS, yielding to $\Omega_{n}=10^{6} / 2$. The average output power of the BS, $P_{\text {avg }}$, is set to either one of the following values: $1 \mathrm{~W}$ and $2 \mathrm{~W}$. We set $P_{\max }=5 P_{\text {avg }}$, and $\eta_{n}=0.5 \forall n$. We consider $M=10^{5}$ epochs, and we depict the average achievable rates for the EHUs for this simulation setup. With these calculated average achievable rates, $\bar{R}_{n}, \forall n$, we can calculate the desirable metrics-sum-rate and fairness index for this system.

Figure 4 depicts the sum-rate over the uplink when NOMA or PF scheduling is employed in the WPCN with respect to the number of EHUs and the average BS power, $P_{\text {avg }}$. As a baseline we use TDMA-based WPCN proposed in [16], where the sum-rate is maximized by optimizing the durations of the EH and IT phases and the BS output power. It can be observed that NOMA achieves the same sum-rate for the same number of EHUs as TDMA, and PF scheduling achieves much smaller sum-rate due to the selection of a single EHU for uplink transmission in each epoch.

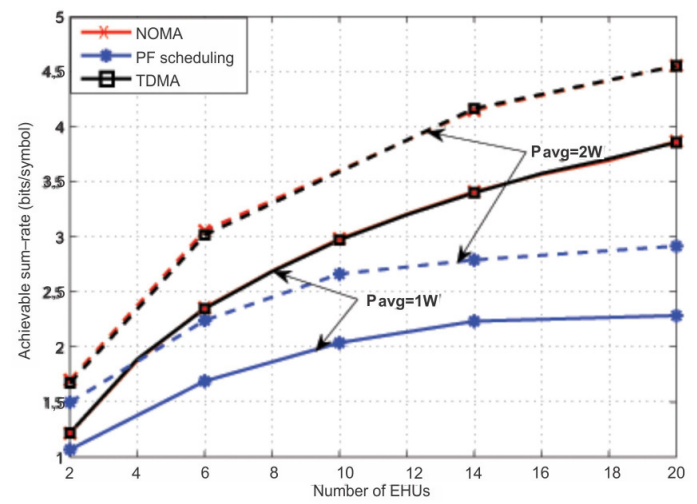

Fig. 4. Achievable sum-rate vs. number of EHUs

In Figure 5, we show the system fairness for the schemes with respect to the number of EHUs and the average BS power, $P_{\text {avg }}$. The system fairness is described by the Jain's fairness index, defined by [17]:

$$
J\left(\bar{R}_{n}\right)=\frac{\left(\sum_{n=1}^{N} \bar{R}_{n}\right)^{2}}{N \sum_{n=1}^{N} \bar{R}_{n}^{2}},
$$

where $\bar{R}_{n}$ is the achievable rate, defined by (3). Note that a higher value of $J\left(\bar{R}_{n}\right)$ indicates a higher degree of system fairness. It can be observed that both NOMA and PF schemes provide substan- 
tial fairness enhancement compared to the baseline TDMA scheme.

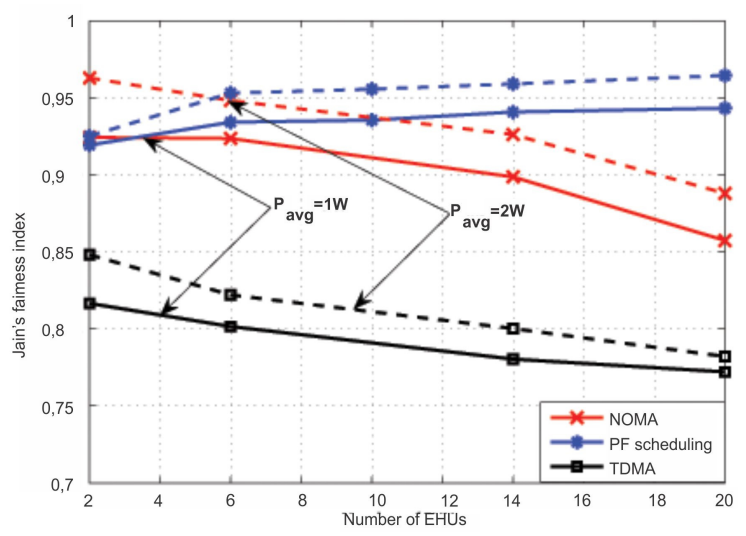

Fig. 5. System fairness vs. number of EHUs

The proposed schemes achieve greater fairness for the same number of EHUs when the average BS power $P_{a v g}$ increases. On the other hand, TDMA attains smaller improvement of the fairness for larger $P_{\text {avg }}$. Although NOMA achieves great level of fairness, it can be observed that the level of fairness decreases with the number of EHUs. On the other hand, the number of EHUs has positive impact for the fairness when PF scheduling is employed, and the results show that PF scheduling outperforms NOMA in terms of system fairness for larger number of EHUs.

\section{CONCLUSION}

In this paper, we propose two schemes that tackle the tradeoff between the uplink sum-rate and system fairness in the WPCNs. Compared to the WPCNs employing TDMA scheme, both proposed schemes significantly enhance the system fairness. The NOMA scheme preserves identical sum-rate as compared to TDMA scheme, and outperforms PF scheduling in terms of achievable sum-rate, thus delivers balanced trade-off between sum-rate maximization and fair resource allocation among the EHUs.

\section{A P P E N DIX A PROOF OF THEOREM 1}

By interchanging the order of summation and using the properties of the logarithmic function the objective function of (4) is transformed as

$$
\frac{1}{M} \sum_{i=1}^{M}\left(1-\tau_{i}\right) \log \left(1+\frac{p_{i} \tau_{i} b(i)}{1-\tau_{i}}\right),
$$

where $b(i)$ is given by (7). The optimization problem (4) with the new objective function (18) is non-convex due to the products and ratios of the optimization variables $p_{i}$ and $\tau_{i}$. Therefore, we reformulate the problem by introducing the change of variable $e_{i}=p_{i} \tau_{i}$, and transform (4) into convex problem in terms of $e_{i}$ and $\tau_{i}$, as

$$
\underset{e_{i}, \tau_{i}, \forall i}{\operatorname{Maximize}} \frac{1}{M} \sum_{i=1}^{M}\left(1-\tau_{i}\right) \log \left(1+\frac{e_{i} b(i)}{1-\tau_{i}}\right),
$$

s.t.

$$
\begin{aligned}
& \bar{C} 1: \frac{1}{M} \sum_{i=1}^{M} e_{i} \leq P_{a v g} \\
& \bar{C} 2: 0 \leq e_{i} \leq P_{\max } \tau_{i}, \forall i \\
& \bar{C} 3: 0<\tau_{i}<1, \forall i .
\end{aligned}
$$

The Lagrangian of (19) is given by

$$
\begin{gathered}
L=\frac{1}{M} \sum_{i=1}^{M}\left(1-\tau_{i}\right) \log \left(1+\frac{e_{i} b(i)}{1-\tau_{i}}\right)- \\
-\lambda\left(\frac{1}{M} \sum_{i=1}^{M} e_{i}-P_{\text {avg }}\right)+\sum_{i=1}^{M} \alpha_{i} e_{i}-\sum_{i=1}^{M} \beta_{i}\left(e_{i}-P_{\max } \tau_{i}\right) .
\end{gathered}
$$

In (20), the non-negative Lagrange multipliers $\lambda, \alpha_{i}$ and $\beta_{i}$ are associated with the constraints $\bar{C} 1$, the left-hand side of $\bar{C} 2$ and the right-hand side of $\bar{C} 2$, respectively, which satisfy the corresponding complementary slackness conditions $\alpha_{i} e_{i}=0, \forall i$, and $\beta_{i}\left(e_{i}-P_{\max } \tau_{i}\right)=0, \forall i$.

By differentiating (20) with respect to $e_{i}$ and $\tau_{i}$, we obtain:

$$
\begin{gathered}
\frac{\partial L}{\partial e_{i}}=\frac{b(i)}{1+b(i) \frac{e_{i}}{1-\tau_{i}}}-\lambda+\alpha_{i}-\beta_{i}=0 . \\
\frac{\partial L}{\partial \tau_{i}}=\beta_{i} P_{\max }+\frac{b(i) e_{i}}{1-\tau_{i}+b(i) e_{i}} \\
-\log \left(1+\frac{b(i) e_{i}}{1-\tau_{i}}\right)=0 .
\end{gathered}
$$

We now consider the following 2 cases. 
Case 1: If $\tau_{i}=0$, then $e_{i}=0$ and no power is allocated to epoch $i$, i.e. $p_{i}^{*}=0$. Since $e_{i}=0$, the slackness conditions require $\alpha_{i}>0$ and $\beta_{i}=0$. From (21) we obtain the condition:

$$
\alpha_{i}=\lambda-b(i)>0 \text {. }
$$

After introducing (7) into (23), we obtain the following condition for the occurrence of this case:

$$
\lambda>N_{0} \sum_{n=1}^{N} \eta_{n} x_{n}^{2}(i)
$$

Case 2: Let us assume $0<\tau_{i}<1$ and $e_{i}=P_{\max } \tau_{i}$. This case corresponds to $p_{i}^{*}=P_{\max }$. The slackness conditions require $\alpha_{i}=0$ and $\beta_{i}>0$. From (21) we obtain the condition:

$$
\beta_{i}=\frac{b(i)}{1+b(i) \frac{P_{\max } \tau_{i}}{1-\tau_{i}}}-\lambda>0
$$

Introducing (24) and $e_{i}=P_{\max } \tau_{i}$ into (22), we obtain (6). Based upon (6) and (24), it can be shown that the sufficient condition for the occurrence of this case is given by

$$
\lambda<N_{0} \sum_{n=1}^{N} \eta_{n} x_{n}^{2}(i)
$$

\section{A P P E N D I X B PROOF OF THEOREM 2}

Although $I_{n}(i)$ is a binary variable, we can relax the constraint $\mathrm{C} 4$ as $0 \leq I_{n}(i) \leq 1$ in order to make the PF optimization problem tractable. After relaxing $C 4$ ' and introducing the change of variables $e_{i}=p_{i} \tau_{i}$, we obtain the following optimization problem:

$$
\underset{e_{i}, \tau_{i}, I_{n}(i)}{\operatorname{aximize}} \sum_{n=1}^{N} \log \left[\frac{1}{M} \sum_{i=1}^{M} I_{n}(i)\left(1-\tau_{i}\right) \log \left(1+\frac{e_{i} a_{n}(i)}{1-\tau_{i}}\right)\right]
$$

s.t.

$$
\begin{aligned}
& \bar{C} 1^{\prime}: \frac{1}{M} \sum_{i=1}^{M} e_{i} \leq P_{a v g} \\
& \bar{C} 2^{\prime}: 0 \leq e_{i} \leq P_{\max } \tau_{i}, \forall i \\
& \bar{C} 3^{\prime}: 0<\tau_{i}<1, \forall i \\
& \bar{C} 4^{\prime}: I_{n}(i) \geq 0, \forall i, n, \\
& \bar{C} 5^{\prime}: \sum_{n=1}^{N} I_{n}(i) \leq 1, \forall i .
\end{aligned}
$$

However, the optimization problem (25) is still non-convex, because of the product $I_{n}(i)\left(1-\tau_{i}\right)$ which appears in the objective function. Nevertheless, similarly to [19, (P4)], we can still apply the Lagrange duality method to solve (13) based on [18, Theorem 1]. In particular, (25) is in the form of [18, Eq. (4)]. For any fixed $\tau_{i}$ and $I_{n}(i)$, the objective function is concave in $e_{i}$. Therefore, for any fixed set of $\tau_{i}, \forall i$ and $I_{n}(i), \forall i$, the objective function of (25) is concave in $\left(e_{1}, e_{2}, \ldots, e_{M}\right)$ and the constraint $\mathrm{C} 1$ is affine (i.e. convex $)$ in $\left(e_{1}, e_{2}, \ldots, e_{M}\right)$. According to $[18$, Definition 1], the time-sharing condition is thus satisfied, implying zero duality gap.

The Lagrangian of (25) is as follows:

$$
\begin{aligned}
L= & \sum_{n=1}^{N} \log \left[\frac{1}{M} \sum_{i=1}^{M} I_{n}(i)\left(1-\tau_{i}\right) \log \left(1+a_{n}(i) \frac{e_{i}}{1-\tau_{i}}\right)\right] \\
- & \lambda\left(\frac{1}{M} \sum_{i=1}^{M} e_{i}-P_{\text {avg }}\right)+\sum_{i=1}^{M} q_{i} e_{i}-\sum_{i=1}^{M} \mu_{i}\left(e_{i}-P_{\max } \tau_{i}\right) \\
& +\alpha_{n, i} I_{n}(i)-\beta_{i}\left(\sum_{n=1}^{N} I_{n}(i)-1\right),
\end{aligned}
$$

where the Lagrange multiplier $\lambda>0$ is associated with the constraint $\bar{C} 1$, whereas the non-negative Lagrange multipliers $q_{i}$ and $\mu_{i}$ correspond to the left-hand side and the right-hand side of $\bar{C} 2$, respectively, and Lagrange multipliers $\alpha_{k, i}$ and $\beta_{i}$ correspond to $\bar{C} 4^{\prime}$ and $\bar{C} 5^{\prime}$, respectively.

By differentiating $L$ with respect to $I_{n}(i), \tau_{i}$ and $e_{i}$, we obtain the following system of 3 equations:

$$
\begin{gathered}
\frac{\partial L}{\partial I_{n}(i)}=\frac{r_{n}(i)}{\bar{R}_{n}}+\alpha_{n, i}-\beta_{i}=0 \\
\frac{\partial L}{\partial \tau_{i}}=\sum_{n=1}^{N} \frac{I_{n}(i)}{\bar{R}_{n}}\left(-\log \left(1+\frac{a_{n}(i) e_{i}}{1-\tau_{i}}\right)-\frac{\frac{a_{n}(i) e_{i}}{1-\tau_{i}}}{1+\frac{a_{n}(i) e_{i}}{1-\tau_{i}}}\right) \\
+\mu_{i} P_{\max }=0 \\
\frac{\partial L}{\partial e_{i}}=\sum_{n=1}^{N} \frac{1+a_{n}(i) \frac{e_{i}}{1-\tau_{i}}}{\bar{R}_{n}}-\lambda+q_{i}-\mu_{i}=0
\end{gathered}
$$


The complementary slackness are given by

$$
\begin{gathered}
\lambda\left(\frac{1}{M} \sum_{i=1}^{M} e_{i}-P_{a v g}\right)=0, \\
q_{i} e_{i}=0, \forall i, \\
\mu_{i}\left(e_{i}-P_{\max } \tau_{i}\right)=0, \forall i, \\
\alpha_{n, i} I_{n}(i)=0, \forall i, n, \\
\beta_{i}\left(\sum_{n=1}^{N} I_{n}(i)-1\right)=0, \forall i,
\end{gathered}
$$

where $q_{i} \geq 0, \mu_{i} \geq 0, \alpha_{n, i} \geq 0$, and $\beta_{i} \geq 0$.

We divide the rest of the proof in two parts: Scheduling policy (part 1) and optimal power and time allocation (part 2).

\section{Part 1}

First, let us focus only on (27) and its corresponding slackness conditions (33)-(34). Without loss of generality, let us assume a WPCN consisting of 2 EHUs ( $a$ and $b$ ). From (27), we have:

$$
\frac{\partial L}{\partial I_{a}(i)}-\frac{\partial L}{\partial I_{b}(i)}=\frac{r_{a}(i)}{R_{a}}-\frac{r_{b}(i)}{R_{b}}=-\alpha_{a i}+\alpha_{b i}
$$

Case 1: If the IT phase is not allocated to any user from complementary slackness it follows that $\alpha_{a, i}>0$ and $\alpha_{b, i}>0$. From (35) we obtain:

$$
\frac{\partial L}{\partial I_{a}(i)}-\frac{\partial L}{\partial I_{b}(i)}=\frac{r_{a}(i)}{R_{a}}-\frac{r_{b}(i)}{R_{b}}=\alpha_{b, i}-\alpha_{a, i}=0,
$$

thus $\alpha_{a, i}=\alpha_{b, i}$ and the probability for it to happen tends to zero. We conclude that the IT phase must be allocated in each epoch.

Case 2: If $0<I_{a}(i)$ and $0<I_{b}(i)$, then $\alpha_{a, i}=0$ and $\alpha_{b, i}=0$. Now we derive:

$$
\frac{\partial L}{\partial I_{a}(i)}-\frac{\partial L}{\partial I_{b}(i)}=\frac{r_{a}(i)}{R_{a}}-\frac{r_{b}(i)}{R_{b}}=0,
$$

or $\frac{r_{a}(i)}{R_{a}}=\frac{r_{b}(i)}{R_{b}}$, which also has probability tending to zero.
Case 3: Lastly, if the IT phase is allocated to user $a$ only, then $I_{a}(i)=1$ and $I_{b}(i)=0$, which in turn implies that $\alpha_{a, i}=0$ and $\alpha_{b, i}>0$ due to the complimentary slackness condition. From (35) it follows:

$$
\frac{\partial L}{\partial I_{a}(i)}-\frac{\partial L}{\partial I_{b}(i)}=\frac{r_{a}(i)}{R_{a}}-\frac{r_{b}(i)}{R_{b}}=\alpha_{b, i}>0 .
$$

From the fact that $\log x$ is a strictly concave function and the previous equation it follows that the optimal scheduling policy is thus given by (14).

\section{Part 2}

Let EHU $s_{i}$ be the scheduled user in epoch $i$. Now, (28) and (29) become:

$$
\begin{gathered}
\frac{\partial L}{\partial \tau_{i}}=\frac{I_{s_{i}}(i)}{\bar{R}_{s}}\left(-\log \left(1+\frac{a_{s_{i}}(i) e_{i}}{1-\tau_{i}}\right)-\frac{\frac{a_{s_{i}} e_{i}}{1-\tau_{i}}}{1+\frac{a_{s_{i}} e_{i}}{1-\tau_{i}}}\right)+ \\
+\mu_{i} P_{\max }=0 \\
\frac{\partial L}{\partial e_{i}}=\frac{\frac{I_{s_{i}}(i) a_{s_{i}}}{1+a_{s_{i}} \frac{e_{i}}{1-\tau_{i}}}}{\bar{R}_{s_{i}}}-\lambda+q_{i}-\mu_{i}=0
\end{gathered}
$$

We consider the following 2 cases:

Case 1: If $\tau_{i}=0$, then $e_{i}=0$ and $I_{s_{i}}(i)=0$ and no power is allocated to epoch $i$, i.e. $p_{i}^{*}=0$.

Case 2: Let us assume $0<\tau_{i}<1$, also $e_{i}=P_{\max } \tau_{0 i}$ and $I_{s_{i}}(i)=1$. This case corresponds to $p_{i}^{*}=P_{\max }$. The slackness conditions require $q_{i}=\alpha_{s, i}=0, \mu_{i}>0$ and $\beta_{i}>0$. From (40), we obtain the inequality condition

$$
\mu_{i}=\frac{a_{s_{i}}}{1+\frac{a_{s_{i}} P_{\max } \tau_{i}}{1-\tau_{i}}}-\lambda R_{s_{i}}>0,
$$

or, equivalently,

$$
\frac{1-\tau_{i}}{\tau_{i}}\left(\frac{1}{\lambda R_{s_{i}}}-\frac{1}{a_{s_{i}}}\right)>P_{\max } .
$$


In order to satisfy the constraint $0<\tau_{0 i}<1$, $\lambda R_{s_{i}}<a_{s_{i}}$ must be satisfied. Introducing $\mu_{i}$ and $e_{i}=P_{\max } \tau_{0 i}$ into (39), we obtain (16).

\section{REFERENCES}

[1] P. Grover, A. Sahai: Shannon meets Tesla: wireless information and power transfer, Proc. IEEE ISIT 2010, pp. 2363-2367, Austin, USA, June 2010.

[2] D. Gunduz, K. Stamatiou, N. Michelusi, M. Zorzi: Designing intelligent energy harvesting communication systems, IEEE Commun. Magazine, 52, 1, 210-216 (Jan. 2014).

[3] C. K. Ho, R. Zhang: Optimal energy allocation for wireless communications with energy harvesting constraints, IEEE Trans. Signal Proccessing, 60, 9, 4808-4818 (May 2012).

[4] H. Ju, R. Zhang: Throughput maximization in wireless powered communication networks, IEEE Trans. Wireless Commun., 13, 1, 418-428 (Jan. 2014).

[5] X. Kang, C. Ho Keong, S. Sun: Optimal time allocation for dynamic-TDMA-based wireless powered communication networks, Proc. IEEE Globecom 2014, Austin, USA, Dec. 2014.

[6] H. Ju, R. Zhang: Optimal resource allocation in fullduplex wireless-powered communication network, IEEE Trans. on Commun., 62, 10, 3528-3540 (Oct. 2014).

[7] T. Takeda, K. Higuchi: Enhanced user fairness using nonorthogonal access with SIC in cellular uplink, VTC 2011, San Francisco, USA, pp. 1-5, 2011.

[8] Z. Ding, Z. Yang, P. Fan, H. V. Poor: On the performance of non-orthogonal multiple access in $5 \mathrm{G}$ systems with randomly deployed users, IEEE Signal Process. Lett., 21, 12, 1501-1505 (2014).
[9] S. Timotheou, I. Krikidis: Fairness for non-orthogonal multiple access in 5G systems, IEEE Signal Process. Lett., 22, 10, 1462-1465 (2015).

[10] H. Chingoska, Z. Hadzi-Velkov, I. Nikoloska, N. Zlatanov: Resource Allocation in Wireless Powered Communication Networks with Non-Orthogonal Multiple Access, IEEE Wireless Communications Letters, 5 (6), 684-687 (2016).

[11] P. Viswanath, D. N. Tse, R. Laroia: Opportunistic beamforming using dumb antennas, IEEE Trans. Information Theory, 46, 6, 1277-1294 (June 2002).

[12] N. Tekbiyik, T. Girici, E. Uysal-Biyikoglu, K. Leblebicioglu: Proportional fair resource allocation on an energy harvesting downlink, IEEE Trans. Wireless Communications, 12, 4, 1699-1711 (April 2013).

[13] H. Chingoska, I. Nikoloska, Z. Hadzi-Velkov, N. Zlatanov: Proportional fair scheduling in wireless powered communication networks, 23rd International Conference on Telecommunications (ICT), May 2013.

[14] Z. Hadzi-Velkov, I. Nikoloska, H. Chingoska, N. Zlatanov, Proportional fair scheduling in wireless networks with RF energy harvesting and processing cost, IEEE Comm. Letters, 20, 10, 2107-2110 (2016).

[15] T.-D. Nguyen, Y. Han: A Proportional Fairness Algorithm with QoS Provision in Downlink OFDMA Systems, IEEE Comm. Letters, 10, 11 (Nov. 2006).

[16] Z. Hadzi-Velkov, I. Nikoloska, G. K. Karagiannidis, T. Q. Duong: Wireless networks with energy harvesting and power transfer: joint power and time allocation, IEEE Signal Process. Letters, 23, 1, 50-54 (Jan. 2016).

[17] R. Jain, D. Chiu, W. Hawe: A Quantitative measure of fairness and discrimination for resource allocation in shared computer systems, Tech. Rep. TR-301, DEC, September 1984.

[18] W. Yu, R. Lui: Dual methods for nonconvex spectrum optimization of multicarrier systems, IEEE Trans. Commun., 54, 7, 1310-1322 (Jul. 2006).

[19] L. Liu, R. Zhang, K.-C. Chua: Wireless information transfer with opportunistic energy harvesting, IEEE Trans. Wireless. Commun., 12, 1, 288-300 (Jan. 2013). 
